\title{
Abusive Interactions: Research in Locked Wards for People with Dementia
}

\author{
Fiona Kelly \\ Dementia Services Development Centre, University of Stirling \\ E-mail: fiona.kelly@stir.ac.uk
}

This paper reports on a study in which unique access to three locked psycho-geriatric wards of a hospital allowed ethnographic exploration into everyday social worlds of fourteen people with dementia. Findings indicate abusive practice in the wards and show that participants in receipt of such practice responded with self-defence and resistance, but ultimately were defeated. In a development of Sabat's (2001) Selfs 1-3 framework, I identify how abusive practice arose due to staffs' inability to recognise different aspects of patients' self. Recommendations for practice include integrating a developed Selfs 1-3 framework into staff training and evaluating its impact on practice.

\section{Introduction}

Dementia is an umbrella term for several degenerative brain conditions, including Alzheimer's disease, multi-infarct dementia and Lewy body dementia. All of these conditions involve variable, progressive loss of cognitive function, beginning with forgetfulness and difficulty concentrating, and progressing to difficulties with reasoning, communicating, recognition and mobility. Along with this bio-medical understanding of dementia, there is now recognition of psychological reactions to losses experienced, and understanding of how people's social contexts influence their experiences of dementia. This bio-psycho-social approach (Sabat, 2008) is adopted throughout this paper.

Dementia, literally meaning 'to be out of one's mind', can be devastating for the person and his/her family, bringing with it the threat of loss: of autonomy, control, a certain future and ultimately the perceived threat of loss of identity. Bryden (2005: 156), in her powerful story of her journey with dementia, talks of her fear of ceasing to be:

We all believe the toxic lie of dementia; that the mind is absent and the body is an empty shell. Our sense of self is shattered with this new label of dementia. Who am I, if I can no longer be a valued member of society? What if I don't know who I am and who I was?

Bryden places responsibility for maintaining her sense of self with herself; with her remaining memories and cognitive abilities, and also with the continued recognition by society of herself as a valued human being. This paper focuses on the latter responsibility and examines the repercussions for people with dementia (and those who care for them) when their selfhoods are not recognised within interaction. This is a group of people who, because of their perceived inability due to cognitive impairment, have little legitimate voice in society, and are therefore at risk of unseen abusive practice. While focussing on 
the experiences of people with dementia, it is anticipated that the ideas and concepts raised here will be applicable when considering interactions with other groups of people who may be vulnerable, marginalised or oppressed.

In this reported study, 14 people with dementia living in three locked long-term wards of an institution gave ongoing consent (Dewing, 2002) for me to explore their everyday lives. Ongoing consent means observing for, and following, visual or verbal cues indicating continued, or withdrawal of, consent. Fieldwork was carried out, one ward at a time, over six months ${ }^{1}$ and used multiple methods - observation and conversation, Dementia Care Mapping (Bradford Dementia Group, 1997), ${ }^{2}$ video recording and extensive fieldnotes - to explore the responses of participants with dementia, in terms of their well- or ill-being and expressions of self, to the different types of interaction they experienced in the wards and during creative sessions facilitated by occupational therapy (OT) staff (see Kelly, 2009). Potential participants were selected on the basis that they were long-term patients in the hospital, they had a diagnosis of a dementia and they took part in weekly creative sessions facilitated by OT staff. The rationale for studying participants' experiences during creative sessions was initially to ascertain whether participating in creative sessions influenced their well-being. What quickly became more important, however, was identifying different types of interactions experienced by participants with dementia, both in the wards and during creative sessions, and to compare how these might influence their well- or ill-being and expressions of self.

This paper only presents data from fieldnotes and video footage to support the main thesis: that self is not lost as dementia progresses, but its expression is contingent on the recognition and support of others within interaction. Findings suggest that, while selfhood endures, it was often unrecognised and unsupported by ward staff, resulting in limiting, limited, damaging or abusive behaviours and contributing to ill-being of those in receipt of such behaviours. I focus on the former finding and explore the implications for staff interaction and for participants with dementia, in terms of their well- or ill-being, when self is unrecognised within interaction. I also examine participants' often unsuccessful attempts to resist abusive practice and their resilience, despite the abusive setting they endured.

Using fieldnotes from the study, I use a developed theoretical understanding of selfhood to explore:

- how we can identify abusive practice through observation of staff interactions with their patients,

- how we can attempt to explain abusive practice in relation to staffs' conceptualisation of the selfhood of their patients,

- the transactional and institutional drivers for abusive practice and their impact on those perpetrating and experiencing it,

- the nature of resistance, defeat and resilience within a conceptualisation of selfhood.

\section{Self in dementia}

Loss of self is a persistent notion when thinking about dementia, predominantly stemming from western philosophical understandings of identity in which the mind is held as superior to and separate from the body (Descartes, 1640) and from medical understandings of dementia, which view it in terms of inevitable loss and decline. 
Despite the person-centred agenda in which we are urged to see the individuality of the person before the label of dementia (Kitwood, 1997), these ideas continue to have a strong influence on how people understand and make sense of dementia and therefore on the experiences of people with dementia themselves (Bryden, 2005).

This paper develops the work of Sabat (2001) who, arguing against the dominant assumption of loss of self as dementia progresses (see Cohen-Mansfield et al., 2000; Davis, 2004), developed the Selfs 1-3 framework to argue for an enduring self in dementia. The three aspects of Self are described below:

Self 1 is the self which expresses first person indexicals ' $I$ ', 'me', 'myself', 'mine' or 'ours'. This aspect of self reflects the fact that each person has one single point of view in the world. By using first person indexicals, we take responsibility for our actions, we locate for others our experiences and feelings and we tell stories about ourselves. Self 1 can be expressed verbally, for example 'That's mine' or 'I like that', or by visually expressing oneself, for example reacting to one's name being called, taking possession of an object or reacting to protect oneself. Sabat (2001) suggests that Self 1 remains largely intact in people with dementia, even with severe cognitive decline.

Self 2 comprises one's physical, mental or emotional characteristics and attributes, and also one's beliefs and desires about them. Some Self 2 attributes have long histories, for example past achievements, while some have more recent ones, for example increasing frailty accompanying an illness. A valued or desired Self 2 attribute can be reclaimed through affirming interaction with others. Positive expressions of Self 2 could include articulating awareness of characteristics and attributes: 'I can do that' or remembering achievements from long ago. Positive visual expressions of Self 2 could be admiring oneself in the mirror. Self 2 can also be expressed in negative terms - 'I can't do that' by reluctance to engage in something or by becoming upset or angry at one's inabilities. Sabat (2001) suggests that Self 2 remains largely intact with cognitive decline, although it is vulnerable when others view disabilities caused by dementia as being attributable to the person rather than the condition. This, malignant positioning, also contributes to a loss of self-worth and will be discussed further below.

Self 3 is the publicly presented aspect of ourselves, the roles we take on and the appropriateness with which we behave in social situations. We have many Selves 3, which we express in different social circumstances: parent, friend, professional, carer or cared-for. Each Self 3 requires different ways of behaving and carries with it different expectations. Expressions of Self 3 could be enacting a familiar role, such as wife or husband, showing regard towards another, being protective, being gracious or showing agency. Self 3 is constructed, sustained, nurtured or changed through interaction with others and is more vulnerable to damage than Selfs 1 and 2. For example, one cannot construct the self of a loving spouse if one's husband or wife does not accord one the status of spouse (Sabat, 2008). Thus, others' positioning of people with dementia help to define, strengthen or weaken their social identities (Sabat, 2001). Negatively positioning people with dementia based on physical or cognitive difficulties is to position them in a potentially malignant way (Sabat, 2008). This renders people with dementia particularly vulnerable in social situations, as they depend on the affirmation and co-operation of others to co-construct (Snyder, 2006) and support a valued Self 3.

Sabat (2001) has been pivotal in implicating the interactions of others in causing damage to selfhood of people with dementia. Kelly (2009) has developed his ideas to include the concepts of recognised, unrecognised, supported and unsupported self within 
interaction and argues that recognising and supporting self (or not) can lead to profoundly different interaction types with marked impact on well- or ill-being of those in receipt of such interactions. In practice, these concepts are not discrete; different combinations will operate together (for example, recognised and supported self, or recognised and unsupported self), but for simplicity they will be described separately. This paper considers the implications for staff interaction and participant well-being of non-recognition of self; it is only when self is recognised that steps can be taken within interaction to support its expression. This fundamental aspect of interaction is captured by Taylor (1994: 25), who, writing in the context of apartheid, describes the consequences of non-recognition of selfhood by others:

Our identity is partly shaped by recognition or its absence, often by the misrecognition of others, and so a person or group of people can suffer real damage, real distortion, if the people or society around them mirror back to them a confining or demeaning or contemptible picture of themselves. Non-recognition or mis-recognition can inflict harm, can be a form of oppression, imprisoning someone in a false, distorted and reduced mode of being.

This paper provides evidence of the continued non-recognition of a marginalised group of people in institutional care and illustrates how such non-recognition imprisoned them, and care staff, within negative cycles of interaction and ultimately in reduced modes of being.

\section{Unrecognised self in practice}

This concept illustrates instances where participants' Selfs $1-3$ were not recognised within interaction. There were no instances where OT staff failed to recognise participants' self during their interactions with them. However, there were many fieldnote entries which suggested that ward staff did not recognise Selfs 1-3. Fieldnote entries document that they engaged in negative behaviours, including physical (pulling, pushing), emotional (shouting, inducing fear), restraint (physical, chemical) and neglect (ignoring distress or need). These often occurred in combination and indicated that ward staff did not recognise their patients' individuality, their remaining abilities and wishes, their personae or their roles (i.e. their different aspects of self). Below is a typical fieldnote extract which illustrates a generalised lack of awareness by staff of their patients as people with social, physical, occupational, relational or emotional needs:

The staff are in the big sitting room chatting together. Someone is rattling persistently on the front door, another is calling loudly and someone else is sobbing. Hannah has been left sitting in the little sitting room and is now sitting in isolation.

In this example, ward staffs' interactions with their patients were non-existent to the detriment of their well-being, as seen in their attempts to get out, their isolation and their distress. This non-existent, neglectful, type of behaviour seemed to be most insidious because it involved the omission or absence of any interaction or remedial practice or any recognition that remedial action was required as this fieldnote extract below demonstrates:

15.00 - I look around to make sure that every one is all right and I spot one of the men lying on the floor. I go to check on him and see that he is sleeping ... I go to look for someone, but 
they are all on their break ... the break goes on and on. I catch a care assistant at about 15.30, and I tell her that the man is lying on the floor sleeping. She replies that they know he is on the floor and that they are leaving him there for now, because at least 'he's not getting up to anything'... After nearly $1 \frac{1}{2}$ hours on the floor, the staff finally attend to him ...

This is a clear case of neglect; it was more convenient for the staff to leave him on the floor, despite the fact that this was an undignified, uncomfortable and potentially unsafe position to be in and it illustrates ward staffs' apparent non-recognition of this man as someone who should still have his dignity, comfort and safety respected and maintained, regardless of severity of cognitive impairment.

The most abusive interactions were those where ward staff violated different aspects of self and where physical abuse resulted, as this field note extract below demonstrates. Ward staff are taking Florence to the toilet:

Hardly had the toilet door closed when I heard Florence shouting and then the care assistant shouting back. Two other staff move quickly to the bathroom and it becomes suddenly noisy; loud voices and underneath, the sound of Florence wailing. Suddenly the bathroom door opens and out comes the care assistant, backwards, with Florence facing her and pushing her with her arms outstretched. The care assistant is half laughing, half cross, but Florence is distressed: 'Oh me me.' Two staff manoeuvre Florence further down the corridor and leave her there sobbing. I go to her and sit beside her, I put my hand gently on her arm and try to comfort her, she twitches violently a few times, but then her body relaxes and the twitching stops. She pulls her blanket tightly round her neck and partially over her head, as if wanting to hibernate. Her eyes close, her head sinks down, she closes up within the warmth of the blanket. I leave her to sleep, a pitiful lonely sight.

Here, staff did not recognise Florence's Self 2 - her remaining ability and her desire to independently care for herself - nor her Self 3 - her proud, private persona - thus their initial interaction with her was one of disempowerment and insensitivity. Florence strongly resists what she sees as an assault on her selfhood (here she expresses Self 1 a normal reaction to a perceived threat), however staff counter-react both in strength and numbers and the end result is one of defeat. The critical point in this interaction, and one where knowledge and understanding of self might have prevented escalation of abusive practice, is recognition that Florence expressed a normal Self 1 when she reacted aggressively to a perceived threat. Recognition that one's actions instil fear in another, particularly in a care environment, should be a trigger to modify one's interactions in order to reassure the person that no threat is intended. In Florence's case, staffs' initial non-recognition of the reason for her aggression and their subsequent counter-reaction to Florence's resistance resulted in a cycle of negative interaction with inevitable negative consequences for all parties. This transactional nature of interactions will be explored in order to further explain why such interactions were so pervasive in these wards.

\section{A transactional process within practice}

I identified broad interactional processes which appeared to contribute to and sustain abusive practices in these wards: initial labelling of the person as aggressive (even when there was no sign of aggression at the time of the interaction), resulting in an aggressive approach to the participant, followed by an aggressive or defensive response 
from the participant and resulting in an escalation of abusive practice by staff. This is the transactional process of interaction (Sameroff and MacKenzie, 2003) and can be illustrated as: A presents a stimulus, which elicits a response from B, which elicits a further response from A, which elicits a further response from B. In this model, outcomes of interactions are the product of the combination of the individual and his/her experience (Sameroff and MacKenzie, 2003), thus there is a continual dynamic between each individual and his/her physical or psycho-social environment in which each influences the other (Fruzzetti et al., 2005). Although primarily used in child development and developmental psychopathology, this model is also used in relationship counselling and is useful in illuminating the potential for 'reciprocal amplifying processes' (Sameroff and MacKenzie, 2003: 622) in influencing the interactions that occurred between ward staff and participants with dementia in this setting.

Florence's experience can be understood using the transactional process and illustrates how, without conscious or ill intent, staff and patients can become locked into negative spirals of action, reaction and interaction with resultant ill-being, particularly of the person with dementia. These types of interactions can be tackled through educating staff of their roots and training them in techniques to break the cycle (Fruzzetti et al., 2005). Ultimately, though, this can only be successful with wider commitment from policy-makers and practitioners throughout the hierarchy of care provision (Innes, 2009).

However, not all practices, particularly neglectful ones can be understood as a transactional process - in neglectful practices, there is no initial staff action to initiate a transactional process. For these cases, it is useful to explore the nature of the institutional environment that staff worked in and patients lived in and which contributed to staffs' non-recognition of their patients as sentient beings.

\section{Institutional abuse and corruption of care}

Although this paper explores individual practice, it is important to remember that ward staff worked within a system which was time- and task-oriented and which gave little scope for innovative practice, such as engaging in reminiscence or singing while carrying out care. In this setting, it was clear that institutional abuse (Glendinning, 1999) occurred, with ward staff also being victims of this in terms of inadequate resources, training and mentorship. Garner and Evans (2000) contend that a system that spends so little of its gross national product on health and social care is itself abusive. Institutional abuse includes individual acts or omissions and managerial failings in which the regime of the institution itself may be abusive and is characterised by:

- poor staff/patient ratio,

- excessive, unquestioned use of restraint,

- large, unhomely wards with poor lighting,

- poor catering, little choice,

- meals served to suits needs of institution,

- lack of mental stimulation,

- lack of privacy,

- generalised care, 
- inadequate staff training,

- poor workplace morale.

(Bennett et al., 1997)

Apart from the first point (the wards were well staffed), all of these elements of institutional abuse were evident in the wards, making positive change difficult to achieve on an individual level. Here from my fieldnotes is an example of excessive and apparently unquestioned use of chemical restraint for the convenience of staff:

The staff nurse comes over to check on a man who is sleeping soundly in a reclining chair. He tells me he is a bit concerned because he sedated him after lunch because he was 'getting worked up' - trying to take his shirt off and getting aggressive, and the medication seems to have hit him harder than he had anticipated, 'but he's still alive' he remarks as he walks away.

The inappropriate prescribing and use of antipsychotic medication in care settings is of growing concern (Alzheimer Scotland, 2008; Brimelow and Lyons, 2009), with evidence of serious detrimental effects of their overuse on people with dementia, including decrease in cognitive function (Ballard et al., 2005) and an increase in the mortality rate (Gill et al., 2007). The All-Party Parliamentary Group on Dementia (APGD, 2008) enquiry into the use of antipsychotic medication in care homes revealed that over-prescribing is often in response to 'challenging' behaviour resulting from non-recognition by staff of their patients' needs. Thus, non-recognition of self appears to be a fundamental contributor to such institutional abuse. Such abusive practices, according to Wardhaugh and Wilding (1993: 5) amount to a corruption of care and constitute an:

active betrayal of the basic values on which the organisation is supposedly based. It is much more than a passive neglect of the principles of good practice. It amounts to an active abuse of a position of responsibility and of a client's fundamental human rights.

In addition to institutional abuse and corruption of care, there was lack of leadership and staff supervision in these wards: crucial elements in promoting and maintaining good practice. This is a widespread issue identified by the APGD (2008) and contributes to the entrenchment of institutional practices. The implications of abusive practice are wide and, as illustrated, included negative cycles of interaction, escalation of aggression and increasing use of physical and chemical restraints, all resulting in poor physical, social and emotional outcomes for the person with dementia, ward staff and others. Indicators of damage to patients and participants resulting from abusive practice included unattended sadness or grief, sustained anger, anxiety, boredom, apathy and withdrawal, despair and physical discomfort (Bradford Dementia Group, 1997: 5). These were common sights in the wards, not to be attributed to dementia, but to the poor psycho-social environment participants found themselves in. While on an individual practice level it is difficult to confront and change institutional abuse, I propose that it is possible to break the negative transactional nature of interactions that occur by training staff to recognise and support Selfs $1-3$ as they carry out care. 


\section{Resistance, defeat and resilience}

Florence's example shows the implications for the person with dementia who tries to resist abusive practice. Florence's was not an isolated experience as this fieldnote extract shows:

There is a commotion from the dining room, crashing and then staff shouting. I can't see what is happening. A minute or so later there is more shouting, and the staff nurse and a male care assistant appear with Joe, hustling him into the sitting room. He is angry and shouting and trying to hit out, but the staff are bigger and stronger than he is, and shout louder. The staff bundle Joe into a chair and shout at him, He hits out, but is restrained; I see fear in his face.

Those, like Joe and Florence, who tried to resist, met excessive force and usually were rapidly outnumbered as the transactional process of interaction took effect. Because staff did not recognise this as a normal response to a perceived and sometimes actual threat, they labelled these participants as aggressive and behaved towards them in an increasingly aggressive manner, breaking their will to resist further.

However, despite the social and interactional poverty and the climate of institutional abuse in these wards, some participants and patients (notably those who did not offer aggressive resistance), showed astounding resilience through showing compassion towards each other and persisting in expressing self. Resilience is seen when people cope, adapt and behave in positive ways in spite of adversity. In the fieldnote extract below, Hannah had been sitting in distress - rocking and whimpering as she often did. Kate, who had no verbal communication, spent most of the day sleeping in a chair and only woke up in the evening. On this occasion, Kate has woken up and is walking slowly, hesitatingly around the sitting room, engaging with no-one:

Hannah is distressed. Kate goes over to her and stands looking down at her. Hannah smiles at her warmly, holding out her hands towards her and Kate smiles back. Kate bends down towards Hannah and Hannah strokes her face and Kate smiles and blinks and stands up again and drifts away.

This short, but significant, exchange between Hannah and Kate demonstrates Kate's remaining ability to engage, reach out to comfort and to reciprocate, (Selfs 1 and 3) despite her seemingly severe cognitive impairment. It also demonstrates that, despite Hannah's distress, she too is able to reach out and engage (Selfs 1 and 3). In this exchange, both demonstrate their resilience' behaving positively towards each other despite the poor psychosocial environment they lived in, and both experience increased well-being for a short while.

This second example of resistance is a type I observed many times - driven by a desire to remain occupied (Self 3). Here from my fieldnotes:

John is round the corner tidying packets of incontinence pads that are sitting on boxes. He is concentrating and working hard ... but a care assistant comes and takes him by the hand and pulls him to a chair. He sits for about three seconds before he gets up again and goes back over to the boxes. Despite two more admonishments by staff, he continues to work until he is taken to the toilet. 
Here is a more pragmatic form of resilience; John quietly persists in finding occupation despite admonishment and removal by the ward staff, and he succeeds for a short time. The striking fact about John's encounters with staff is that his lack of physical resistance means he is not subject to reactive abusive practice from them and therefore his experience in the ward is less fraught. Whether he might once have resisted and has learned not to or whether he was always more passive is unknown and would have required longitudinal study. What is clear is that he, and others whose resistance was non-aggressive, faired better in these wards, despite their non-recognised selfhoods.

\section{Impact of abusive practices on the observer}

Researching in such a setting inevitably had an impact on me. After receiving sharp admonishments from particular care assistants, I constantly tried to avoid potential conflict and became angry with myself when I realised that my fear of conflict influenced how I interacted with participants. For example, one day, following an incident when a care assistant shouted at us when William kissed me good-bye:

William calls me over, stretches out and takes my hand and bends his head down to kiss it, but I say, knowing that $X$ is on: 'William, you and I got a row last week, I don't want you to get another one.' He understands, but is put out and waves me away and I immediately feel that I have let him down by denying him what really is just normal social contact...

The memory of the previous incident, and my need to protect myself, influenced how I subsequently interacted with William, to his detriment. At times like this, I felt that their intimidation had rendered me impotent and I was unable to intervene. This was particularly the case following the incident when the man was left lying on the floor:

I want to cry, with sorrow, disbelief, despair and anger at myself for being cowardly and for not insisting that the staff lift him off the floor.

My increasing distress for the plight of participants illustrate that fieldwork in such a setting can be an uncomfortable experience for the researcher; she/he will have to grapple with emotional and practical difficulties and dilemmas, negotiate the balance between intervening and interfering (Innes and Kelly, 2007) and will have to make decisions that reflect her/his own enduring humanity. Yet, exposure to and insights gained from such emotional danger (Lee-Treweek, 2000) have added immeasurable depth to understanding the everyday social worlds of people with dementia in institutions and in particular to the ways in which non-recognition of self by care staff can profoundly influence practice and the well-being of those in receipt of such practices.

\section{Conclusion}

I have described findings from a study in which unique access to a marginalised group of people allowed for detailed study of their social worlds and examination of the reasons for and consequences of different types of staff practices. In an integration of the works of Kitwood (1997) and Sabat (2001), I have suggested that abusive practices arose 
through non-recognition by ward staff of their patients' selfhoods and through increasingly negative transactional processes within interaction. Deeper underlying factors, including institutional abuse and corruption of care, contributed to the pervasive nature of abusive practices observed in this setting. I have shown that, despite the psycho-social poverty of the wards, participants and patients demonstrated selfhood in a variety of ways, including resistance and resilience. However, because staff did not recognise resistance as expression of self, their interactions were often abusive, and without recognition of resilience as expression of self, there was little remedial or supportive action taken.

Although a small study, it supports findings that indicate that abusive practices are not uncommon within long-term and institutional settings (Action on Elder Abuse, 2004) and which argue that without radical change in recruitment, training, mentoring and reporting and disciplinary procedures, such practices will continue. Of fundamental importance is a shift in thinking and practice concerning people with dementia, regardless of cognitive ability. We must move away from deterministic, self-fulfilling practice which reinforces loss of ability, role and identity and assumes increasing loss of communication, will and desire, to practice in which potential is recognised and supported, and in which the subtleties of behaviour are recognised as communication of some aspect of self. Nonrecognition of self is a fundamental stumbling block to good practice. The inclusion of theoretical understandings of self into staff training programmes and evaluation of its impact on practice are imperative if change is to occur.

\section{Notes}

1 Ethical approval was granted from the Multi-centre Research Ethics Committee (Scotland), the NHS Local Research Ethics Committee and the Research Ethics Committee of the Department of Nursing and Midwifery, University of Stirling.

2 DCM is an observational tool which evaluates the impact of care practices on the well-being of people with dementia in formal care settings. Its aim is to qualitatively and quantitatively measure how person-centred philosophy is applied in care environments and experienced by those with dementia.

\section{References}

Action on Elder Abuse (2004), Hidden Voices: Older people's Experiences of Abuse, London: Help the Aged.

All-Party Parliamentary Group on Dementia (2008), 'Always a last resort: inquiry into the prescription of antipsychotic drugs to people with dementia living in care homes', House of Commons, London, available at http://www.alzheimers.org.uk/downloads/ALZ_Society_APPG.pdf [accessed 16 April 2009].

Alzheimer Scotland (2008), 'Antipsychotic drugs and dementia briefing paper', available at http://www. alzscot.org/pages/policy/antipsychoticdrugsbriefing.htm [accessed 14 April 2009].

Ballard, C., Margallo-Lana, M., Juszczak, E., et al. (2005), 'Quetiapine and rivastigmine and cognitive decline in Alzheimer's disease: randomised double blind placebo controlled trial', British Medical Journal, 330, 874-8.

Bennett, G., Kingston, P. and Penhale, B. (1997), The Dimensions of Elder Abuse: Perspectives for Practitioners, London: Macmillan Press.

Bradford Dementia Group (1997), Dementia Care Mapping Manual, 7th edn, University of Bradford.

Brimelow, S. and Lyons, D. (2009), Remember, I'm Still Me, Edinburgh: Care Commission/Mental Welfare Commission. 
Bryden, C. (2005), Dancing with Dementia, London: Jessica Kingsley Publishers.

Cohen-Mansfield, J., Golander, H. and Arnheim, G. (2000), 'Self-identity in older persons suffering from dementia: preliminary results', Social Science and Medicine, 51, 3, 381-94.

Davis, D. (2004), 'Dementia: sociological and philosophical constructions', Social Science and Medicine, 58, 2, 369-78.

Descartes, R. (1640), 'Meditations on the first philosophy in which the existence of God and the distinction between mind and body are demonstrated', in R. Wilkinson (2002), Minds and Bodies, Milton Keynes: The Open University.

Dewing, J. (2002), 'From ritual to relationship: a person-centred approach to consent in qualitative research with older people who have a dementia', Dementia, 1, 2, 157-71.

Fruzzetti, A., Shenk, C. and Hoffman, P. (2005), 'Family interaction and the development of borderline personality disorder: a transactional model', Development and Psychopathology, 17, 1007-30.

Garner, J. and Evans, S. (2000), Institutional Abuse of Older Adults, London: Royal College of Psychiatrists.

Gill, S., Bronskill, S., Normand, S. et al. (2007), 'Antipsychotic drug use and mortality in older adults with dementia', Annals of Internal Medicine, 146, 11, 775-86.

Glendinning, F. (1999), 'The abuse of older people in institutional settings: an overview', in J. Manthorpe, B. Penhale and N. Stanley (eds.), Institutional Abuse: Perspectives Across the Lifecourse, London: Routledge.

Innes, A. (2009), Dementia Studies: A Social Science Perspective, London: Sage.

Innes, A. and Kelly, F. (2007), 'Evaluating long stay settings: reflections on the process with particular reference to dementia care mapping', in A. Innes and L. McCabe (eds.), Evaluation in Dementia Care, London: Jessica Kingsley Publishers.

Kelly, F. (2009), 'Recognising and supporting self in dementia: a new way to facilitate a person-centred approach to dementia care', Ageing and Society, 29 (in press).

Kitwood, T. (1997), Dementia Reconsidered, Buckingham: Open University Press.

Lee-Treweek, G. (2000), 'The insight of emotional danger: research experiences in a home for older people', in G. Lee-Treweek and S. Linkogle (eds.), Danger in the Field: Risk and Ethics in Social Research, London and New York: Routledge.

Sabat, S. (2001), The Experience of Alzheimer's Disease: Life through a Tangled Veil, Oxford: Blackwell Publishers.

Sabat, S. (2008), 'A bio-psycho-social approach to dementia', in M. Downs and B. Bowers (eds.), Excellence in Dementia Care, Berkshire: Open University Press.

Sameroff, A. and MacKenzie, M. (2003), 'Research strategies for capturing transactional models of development: the limits of the possible', Development and Psychopathology, 15, 613-40.

Snyder, L. (2006), 'Personhood and interpersonal communication in dementia', in J. Hughes, S. Louw and S. Sabat (eds.), Dementia: Mind, Meaning and the Person, Oxford: Oxford University Press, pp. 259-76.

Taylor, C. (1994), 'The politics of recognition', in A. Gutmann (ed.), Multiculturalism: Examining the Politics of Recognition, Princeton, NJ: Princeton University Press.

Wardhaugh, J. and Wilding, P. (1993), 'Towards an explanation of the corruption of care', Critical Social Policy, 13, 4-31. 